\title{
Analysis on the Reasonable Application of Fine Arts in the Process of Art Appreciation
}

\author{
Yuan Liu \\ Ningxia Vocational Technical College of Industry and Commerce, Yinchuan, 750001, China
}

Keywords: Art Appreciation, Reasonable application, Fine arts

\begin{abstract}
With the development of the reform of quality-oriented education, art teaching is becoming more and more popular among the students and teachers. This is because art teaching could not only improve the comprehensive quality of the learner, but also could cultivate their aesthetics for appreciation. How to improve the learner's art appreciation level? It is important to reasonably use fine arts in the process of art appreciation. On the basis of the comparison of fine arts, this paper stresses the expression of the reasonable application of fine arts in the process of art appreciation.
\end{abstract}

\section{Introduction}

The main goal of Chinese art appreciation teaching is to required teachers practically help the learner to understand the splendid traditional Chinese art and respect Global diversification culture, and guide the learner to apply the perception, experience and knowledge to the feeling, experiencing and imaging of the art works, and eventually acquire the enjoyment from aesthetics and comprehend art works and art phenomena in the deep level, then profoundly understand art in the cultural situation. For this purpose, art teachers need to conduct the learners to comprehend the art work itself during the process of the analysis of artwork at home and domestic, conduct the students to discuss the external beauty, main current value and drawing techniques of the art work itself, and in the same time they should focus on the time background, art schools, conceptions and thoughts and make them totally expressed. Especially they should focus on the comparison between the art work with the development of human civilization and comparison between different art categories of the same age. Thus, the learners can get profound and exact comprehension to the classic art works form micro perspective and can also get profound comprehension to the epochal character and universality of the art works from macro perspective. For that purpose, the author of this paper thinks that the reasonable application of fine arts in the process of art appreciation can help the learners understand the beauty of are from cultural artistic conception.

\section{Overview of comparative fine arts}

The comparative fine arts refer to use comparative methods to discuss art. In details, that is to gather amounts of different art categories or works from different culture foundations of different nations, different countries, and different cultures. The key point is to analyze the mutual relationships among them. Some scholars once put forward that the research methods of comparative fine arts are changing approach study, form approach study, mutual interpretation approach study and cross approach study and so on. The author of this paper combines it with the teaching contents in the process of art appreciation. From this combination, unexpected teaching effects can be achieved. That is to say, gathering the art works from different countries, different time backgrounds, and different categories, their unique beauties will be revealed. Based on findings of differences and the different characteristics of art works, the aesthetics for art appreciation of the learners can be cultivated. Once the teachers have the competence to apply the knowledge of the competitive fine arts in the practical art teaching, the art appreciation aesthetics of the learners will be raised to the maximum. 


\section{The approaches of the reasonable application of fine arts in the process of art appreciation}

To make competitive fine arts applied in the process of art appreciation with wider range, the author of this paper concludes it to five different teaching approaches. As long as the art teachers reasonably apply those five teaching approaches into the practical process of art appreciation, the teaching effects will be very excellent.

\section{The approach of textual research on origin and development}

The so called approach of textual research on origin and development refers that when teachers are giving lectures on art works, they should not only concentrate on the other work itself, but also concentrate the expression for the Historical cultural environment of the art works, in other words, to tell them how the historical culture environment of the art work is. Through the expression for the historical cultural environment of the art works, learners will clearly understand the sources of the artwork. That is the teaching approach of origin. The meaning of development here refers to the developing direction of the artwork in the social environment afterwards. That's the studying approach of development. For example, when the author of this paper is directing the students to appreciate the famous painting work The portrait of Chi Baishi, the approach of textual research on origin and development is used in this way: The first is to let the students know the basic information about the author Wu Zuoren. He is a modern Chinese oil painter, and when he was young he studied abroad in Europe. As thus, Wu knew a set of orthodox painting techniques. According to this historical circumstance, when the author of this paper is appreciating Wu's The portrait of Chi Baishi, the author of this paper considered the expression of the painting techniques Wu learned in Europe. The second is to let the students know how the Hunters express their origin and development. We must pay attention to how the painters express the cultural knowledge they learned in Europe in their works. Through competitive fine arts we can realize the difference between Wu's works and the works of contemporary artist. Of course we can also make comparisons of Wu's paintings of his early phase in Europe study. As thus, it is easy to see that the subsequent work The portrait of Chi Baishi is not only influenced by foreign art style, but also blend in traditional Chinese art style. This is because since the establishment of new China, national style was popular the field of technology of that time. Deeply influenced by traditional Chinese national art style, Mr. Wu's The portrait of Chi Baishi not only demonstrate strong European art style, but also demonstrates the traditional Chinese art spirit of that time. It is really a seamless joint of European art culture and traditional Chinese national style.

\section{The approach of form comparison}

This approach means to gathering the painting styles, art forms and art expressions of different countries, different nations then make comparisons. The approach of textual research on origin and development mentioned above concentrates on the origin and development of art works, while the approach of form comparison concentrates more on the art language of different categories revealed in the paintings. Through gathering and comparing paintings of the same category of different categories, we can easily comprehend the intention of abstract painting style. The approach of form comparison not only can gather paintings of different art styles and compare, but also can compare the changes of the same art style in different artistic conception periods. The comparison of those art works with different art styles is simple and easy to be understood. The comparison of different artistic conception periods of the same art style is comparatively difficult. So the art teachers have to carry out deeper comparisons in the process of preparation for the lessons. Then the approach will be verified with a real example of the classroom teaching of the author of this paper. When the author of this paper is teaching the famous painter Mondrian's work "tree" to the students, his previous works are expressed, which is not enough. We need a comparison of his series of works with the Tree. From this approach of form comparison, we can clearly tell the students how the modern art transform itself from concrete form art to different abstract art. With this appreciation approach, the students can realize that the first art work related to Mondrian's work "tree" is an extremely vivid copy from the life. In the several works of this painter, He begins to abstract the concrete image of life into a typical tree element. Eventually he gives up the concrete image of the tree and only depends on single line 
and colour to describe the inner structure of the tree, so the abstract art is created. In general teaching process, teachers don't show all the changing status of the tree to the learners. It requires the art teachers to prepare all the works related to the Tree series and show these works during the teaching process. The learners use the approach of form comparison to comprehend more profoundly the changing status of series of the works and comprehend the relationship between concrete and abstract.

\section{The approach of cross verification}

Compared with the two approaches mentioned above, the approach of cross verification is the art appreciation approach with higher level. The approach of cross verification needs the learners to express the art works from the external side but also consider the religious, philosophy, literature and other humanity subject knowledge when they are appreciating the art works. With the connection of other humanity subject knowledge and the works, the originally simplified art works become three dimensional and multileveled to extend to the three dimension space. If the art educators want to use the approach of cross verification with more skills, they need to improve their own professional proficiency and continuously enriching their teaching experience. If the teachers want to apply the approach of cross verification in the teaching practice reasonably, they need to do the cross verification according to the practical teaching content and humanity subject knowledge. Thus the textbook will be thick. That is to say, the art work can be expanded with teaching contents without limitation. In other words, the textbook will be thin, too. The teachers can use simple language to turn the abstract and complicated art works into simple ones. Therefore art educators must keep enriching their own teaching experiences, and apply the approach of cross verification reasonably in the classroom. Thus their personal teaching skills will be improved and the basic skill of art appreciation of the learners will be promoted too.

\section{The approach of situational teaching}

Art is an extremely important human science which has a very strong spirit of humanism. It contains the cultural emotion and cultural background of a certain age. In the process of art appreciation, we should set the art work that we are going to appreciate in the necessary culture background. With the help of modern multimedia teaching methods, with the help of images and videos and other different methods, learners can profoundly study the artistic conception and the humanism spirit behind the art works. The first is to make the learners understand the time background and the related humanism spirit. For example when we are appreciating Raphael's School of Athens, it is necessary to introduce the history of Renaissance and the spirit of humanism. And when we are appreciating ancient Greek sculpture Discobolus, if the learners don't understand the traditional customs about the naked sports of Ancient Greece, when facing body sculptures they will feel at a loss. The art teachers must let the students know that the human body aesthetics conception is based on this. The second is to seek for the help of the music to create reasonable teaching situation to help the learners to get more plentiful and more excellent art appreciation experience. For example, when we are appreciating ancient Chinese landscape paintings, we can play Mountain stream of ancient Chinese Zheng for the students. Thus, The artistic conception of the painting will be demonstrated and it can also lead the students into the mood of meditation. This approach is very helpful in improving the Aesthetic foundation of the learners and help them comprehend the artistic conceptions to make the appreciation more realistic more three dimension and more vivid.

\section{The approach of open teaching}

The art appreciation is not limited in the classroom. It needs to go outside the classroom and use the environment around the school. Thus the connection between school education and society will be realized which will promote the combination of school art and social art education and create the open type art education approach. Therefore teachers can organize learners to visit the local art gallery museum or parkland. The learners will be baptized in the world of art so that they can directly grasp the connection between art and life. At the same time they will experience the charms of excellent art 
works especially the Chinese paintings. If they cannot face the original work they can not feel the charms behind the papers. Thus, the brush work of the paintings can be practically appreciated and achieve enough tension and vigor. There are also sculptures and the constructions with strong sense of third dimension. Only when you're in it, you can experience its charms better.

\section{Conclusion}

In a conclusion, to better adapt to the requirement of quality oriented education and fasten the reform process of Chinese educational system then improve the comprehensive quality of the learners, art educators must stress the teaching methods and positively use diversified teaching methods in the art appreciation teaching. Reasonably use the approach of competitive fine arts to improve the learner's art appreciation to the maximum, and make sure the students can grow up healthily under the background of quality oriented education. Meanwhile we should realize that teaching doesn't have a certain form. We shouldn't use a fixed approach in the art appreciation teaching. We should use the approaches with flexibility according to the practical situation to realize the creative art appreciation teaching.

\section{References}

[1] Course textbook research institute, Art course textbook research institute. Art appreciation. Beijing: People education press, 2004.

[2] Art Course Standard Research Team. Regular senior secondary school art course standard(Experimental) . Nanjing: Jiangsu Education Press, 2004.

[3] Li beilei, He Yun. The research on the competitive fine arts. Journal of SEU(Philosophy and social science edition), 2011(2).

[4] Wu Jia. The application of competitive fine arts in art appreciation in high schools. Arts and science guidance, 2013(7). 